\title{
Política e Fluxo Editorial da Revista Enfermagem Atual In Derme
}

\section{Editorial Policy and Flow of the Journal Nursing Atual In Derme}

\author{
Kátia Simões' $\bullet$ Robson Dias Martins²
}

A Revista Enfermagem Atual In Derme, periódico de acesso aberto, publicado pela Sociedade Brasileira de Enfermagem em Feridas e Estética - SOBENFeE, tem por finalidade difundir o conhecimento nas áreas de atuação da enfermagem. Ela atua na disseminação de pesquisas, estudos e artigos científicos atualizados e relevantes para a comunidade alvo.

O lançamento da revista, no cenário da comunidade cientifica de enfermagem, aconteceu a partir das inquietações e dos debates acerca da formação dos profissionais de enfermagem, as contendas sobre a prática e a evolução do conhecimento da área são propulsoras para a disseminação do conhecimento produzido na área, Nesse contexto, pretende-se cumprir seu papel na formação de profissionais através da comunicação científica eficaz, eficiente e de qualidade.

O periódico possui destaque na comunidade científica de enfermagem com a publicação de artigos que permitam colaborar para as estratégias de atuação profissional. Ela está alinhada com a visão e missão da Instituição que pretende "Desenvolver e estimular", constantemente, os estudos técnico-científicos acerca do cuidado da pessoa portadora de ferida, com qualificação da assistência do enfermeiro que tenha interesse nessa área bem com, com as transformações tecnológicas contemporâneas.

Nesse contexto, a Revista está em processo de reestruturação da plataforma de gestão e acesso, buscando otimizar o fluxo editorial.

A produção de um periódico científico é uma tarefa árdua e profícua que exige o enfrentamento de desafios, inquietações, provocações e dedicação do grupo envolvido. Com o intuito de modernizar e agilizar o fluxo editorial da Revista foi proposto a utilização de plataformas eletrônicas de gestão, modelo utilizado para a administração de periódicos na contemporaneidade. Nesse contexto, após revisão da literatura acerca das principais ferramentas de gestão de periódicos, foi identificado que o software Open Journal Systems (OJS), uma ferramenta livre, utilizada para construção e gerenciamento de revistas eletrônicas, que surgiu a partir da customização do OJS, desenvolvido pelo Public Knowledge Project (PKP), da University of British Columbia, o Open Journal Systems (OJS).

O software traz um conjunto de funcionalidades orientadas e adaptadas ao processo de publicação científica, além de garantir a interoperabilidade com outros sistemas e serviços.

O sistema possibilita a gestão de todo o fluxo editorial, disponibiliza e flexibiliza o processo de editoração de uma revista, desde a submissão do artigo pelo autor, a avaliação pelos pares, a divulgação e arquivamento digital do artigo.

Um forte incentivo para a utilização do sistema OJS é a recomendação da Coordenação de Aperfeiçoamento de Pessoal de Nível Superior (CAPES), que sugere o uso do sistema para padronizar as informações, visto que ele realiza intercambio e preservação de todos os dados da publicação.

O projeto está sendo desenvolvido com as seguintes etapas:

I) Instalação do software OJS,

2) análise de toda a coleção, (edições, números especiais e suplementos),

3) inserção no sistema;

4) exame (não gostei desse termo) do processo de submissão no OJS, bem como o processo editorial, que inclui o cadastro da equipe editorial; ativação e integração do DOI (Digital Object Indentifier), além de outras funções estabelecidas no sistema para o gerenciamento eficaz da revista. 
Atualmente, todo processo editorial da Revista, está alinhado ao sistema eletrônico. Estamos migrando os dados antigos e implantando os fluxos operacionais contemporâneos. Essa reformulação busca dinamizar o processo editorial para autores, avaliadores, gestores e usuários

As etapas para a migração e estabelecimento da revista no sistema OJS requer planejamento, atenção, comprometimento. Espera-se com termino do processo estar com o fluxo administrativo e editorial afinados com o papel que o periódico tem em divulgar o conhecimento cientifico na área de enfermagem. 


\section{REFERENCIAS}

Meadows, Arthur Jack. A comunicação científica. Brasília: Briquet de Lemos; 1999.

Agência USP de Gestão de Informação Acadêmica - AGUIA. Entenda o que é Acesso Aberto. Disponível em: https:// www.aguia.usp.br/apoio-pesquisador/acesso-aberto-usp/ entenda-o-que-e-acesso-aberto/.Acesso em: 19 ago. 2020.
Public Knowledge Project (PKP). Open Journal System - OJS. Disponível em: https://pkp.sfu.ca/ojs/. Acesso em: 10 ago. 2020.

Instituto Brasileiro de Informação em Ciência e Tecnologia. OJS/SEER. Disponível em: http://labcoat.ibict.br/portal/?page_id=15. Acesso em: 12 ago. 2020. 